\title{
Research methods of refined oil from peel calamondin (Citrus microcarpa) from Tien Giang Province, Vietnam
}

\author{
Nguyen Van Tuan', Quyen Ngo Thi $\mathrm{Cam}^{2,3 *}$, and Mai Huynh Cang ${ }^{1 * *}$ \\ ${ }^{1}$ Faculty of Chemical Engineering and Food Technology, Nong Lam University, Thu Duc District, Ho \\ Chi Minh City, Vietnam \\ ${ }^{2}$ Institute of Environmental Sciences, Nguyen Tat Thanh University, Ho Chi Minh City, Vietnam \\ ${ }^{3}$ Faculty of Environmental and Food Engineering, Nguyen Tat Thanh University, Ho Chi Minh City, \\ Vietnam
}

\begin{abstract}
The research on extraction and refining of oil was conducted on the calamondin peels purchased in Thu Duc Market. Them originated from the province of Tien Giang in Viet Nam. The purpose of research evaluation of the quality of refined oil by refining methods such as deposition/filtration, crystallization - suctioning of oil, using $\mathrm{Na}_{2} \mathrm{SO}_{4}$ - filtering of oil, $\mathrm{Na}_{2} \mathrm{SO}_{4}$ suctioning of oil, second extraction and combination all the above methods. The results showed that the initial moisture content of the material was $77.37 \%$, and dry matter content was $8.46 \%$. Extraction at optimum conditions is 60 minutes, $1 / 8$ of raw material / solvent ratio $(\mathrm{w} / \mathrm{v})$, with fresh ingredients and raw material size is small at $1 \div 3.5 \mathrm{~mm}$ the highest oil content was obtained. The essential oil obtained contain a high content of Limonene (over 85\%), which has been shown to be able to inhibit breast cancer, colorectal cancer, control heartburn and gastric reflux, and support the treatment of gallstones containing cholesterol.
\end{abstract}

\section{Introduction}

The bark of Citrus trees such as orange, lemon, and grapefruit has long been used to produce essential oils in industrial countries around the world such as the US and Italy. Citrus essential oil has a pleasant aroma, high levels of Limonene and is widely used in foods and cosmetics [1-5]. Recent studies have also shown that Limonene also dissolve stones, and destroy tumors so it can be used in medicine [6-11]. In Vietnam, especially in the Mekong River Delta, including Dong Thap province, another species of Citrus in the Rutaceae family (orange family) is kink, the common is Citrus japonica Thunb. (Fortunella japonica Swing) is grown everywhere. The peel can be fresh, dried or frozen to extract the essential oils. Studies on calamondin oil have been performed quite a lot in the world but in Vietnam are still very limited. Recently, there have been a few studies on calamondin essential oil [1214].

\footnotetext{
* Correspondence author: ntcquyen@ntt.edu.vn

** Correspondence author: maihuynhcang@hcmuaf.edu.vn
} 
The peel contains many essential oils that are similar toother fruits of the citrus family (Rutaceae) including limonene, $\alpha$ - pinene, $\beta$ - pinene, linalool, geraniol, and citral. In addition, the peel contains flavonoids such as naringosi, hesperidin, diosim, diosmetin, and hesperitinwhich protects the capillary wall, reduces permeability, enhance capillary elasticity and stability, thus helping to prevent accidents from rupture of capillaries, and indirectly lower down the blood pressure. Therefore, people have applied the peel to produce essential oils for human needs [15]. The calamondin peel oil is a transparent liquid with a very pleasant characteristic aroma. The essential oil contains about 25 ingredients, in which the main ingredient of the essential oil is D - Limomene, accounting for over $85 \%$ of the total ingredient. Essential oils of orange, lemon and calamondin have a serene and pleasant aroma in general. In addition to being used as an ornamental plant, the essential oil from the peel has many practical uses in life such as: anti-fungal nail, good sleep, headache treatment, appetite, deodorizing, lowering blood sugar, and reducing flatulence. In addition, calamondin peel oil also helps prevent the development of cancer of the liver, esophagus, colon, and skin. There are many methods of extracting essential oils, namely, mechanical method, distillation method, easy solvent extraction method evaporation, extraction method with non-volatile solvent, using solid adsorbents, using supercritical $\mathrm{CO}_{2}$, and microwave-assisted extraction. In this study, we use the steam-enticing distillation method to extract essential oils from the peels because this method is environmentally friendly, and low cost.

Studies on calamondin essential oil are often studied on the chemical composition of the essential oil [16], the methods of essential oil extraction or the biological activity of the essential oil [17], but very few studies on the refining of the essential oil. Realizing the importance and usefulness of calamondin essential oil, I conducted research on refining the essential oil from the peel of the calamondin. Aim to obtain the highest pure essential oil content after the extraction process.

\section{Material and method}

\subsection{Material}

Calamondin (Citrus microcarpa) fruit is purchased at Thu Duc market, originated from Tien Giang province. The selected fruits are uniform in size $(\varnothing 2.25 \div 3 \mathrm{~cm})$, unripe, bright green color, intact and not stamped. The peel of these fruits was removed before conducting the experiment (Figure 1 and Table 1). Ingredients of kinks: Investigate in $1 \mathrm{~kg}$ of pretreated kitchens, repeat 3 times.

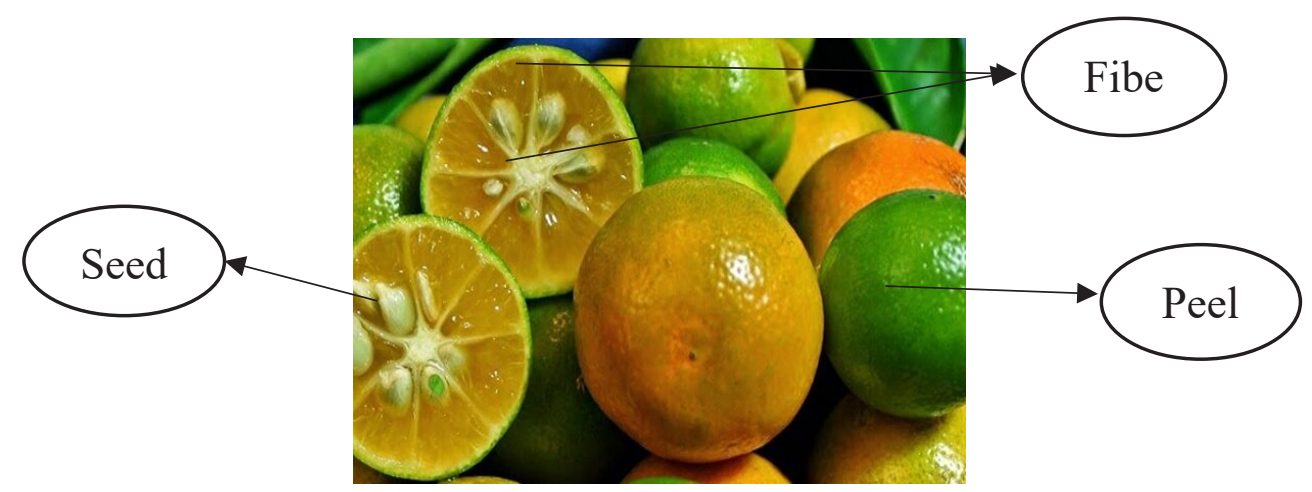

Fig. 1. Components of the calemondin 
Table 1. The composition of the calemondin

\begin{tabular}{|c|c|}
\hline Ingredient & Ratio (\%) \\
\hline Peel & $14,5 \pm 0,5$ \\
\hline $\begin{array}{c}\text { Calamondin and } \\
\text { calamondin kernels }\end{array}$ & $50 \pm 1$ \\
\hline Water switch & $35,5 \pm 1$ \\
\hline
\end{tabular}

\subsection{Method}

After being collected, the peels were washed in cold water and then let dry. Next is the peeling off and removing the intestines. The clogs are stored in a refrigerator at $0-4^{\circ} \mathrm{C}$ for use as a gradual experiment. The peel can be dried before carying out the moisture survey. Next, the peel is weighed and ground with a blender for 1 minute. Then, a steam-enticing distillation system was used to extract essential oils from calamondin peels under the conditions of extraction time, material moisture, material size and raw material ratio raw materials / solvents. The crude oil is condensed in a distillation tube. Essential oil after separating water from the settling vessel is still not completely water-free and clear. $\mathrm{Na}_{2} \mathrm{SO}_{4}$ salt was used to remove water, and to crystallize at $-15^{\circ} \mathrm{C}$. Then, the essential oil was filtered using a filter paper, or a needle. In addition, a second distillation is possible and combined with the above methods.

\section{Results and discussion}

\subsection{Material}

As can be seen in Figure 2, the maturity of the ingredients has an impact on the amount of essential oil obtained. The rind of a ripe (medium-ripe and fully-ripe) calamondin produced less essential oil than the peel of an unripe fruit. As the ripe peel is softer and their biochemical content has changed, thus causing the amount of essential oil obtained from the peel to decrease. Year 2012, Soumaya Bourgou had studied revealed that the ripening stage affects significantly the yield and the composition essential oil. For the four citrus, the highest limonene level was reached already at immature stage which suggests that at least in the case of lemon and for economic purposes, fruits could be harvested at immaturity in order to obtain essential oil with high yield and limonene content [18]. Therefore, the most suitable ripeness of the material for the extraction process is the unripe (green) fruit. 


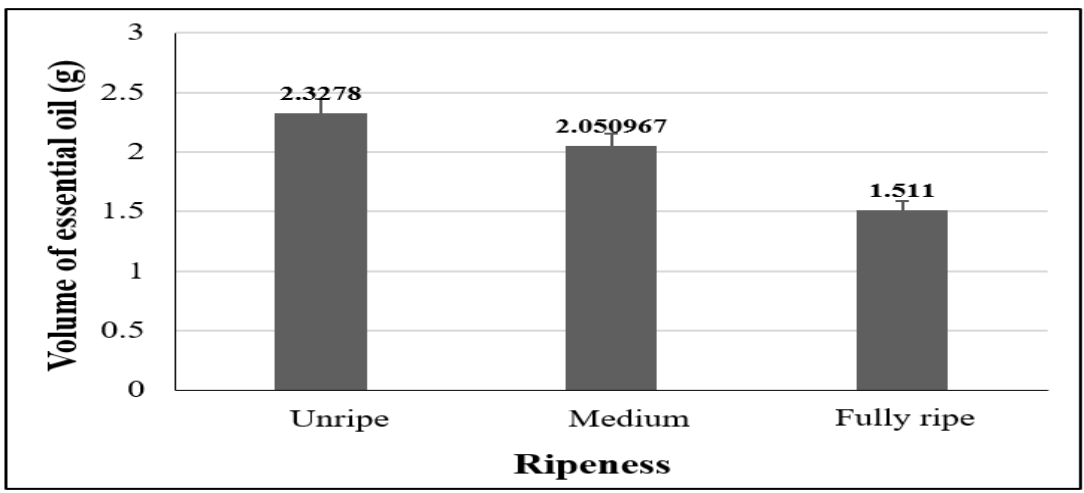

Fig. 2. Effect of the maturity of the ingredients on the amount of essential oil obtained

\subsection{Investigation of material size}

As shown in Figure 3, the size of the material is too big that could hinder the extraction of essential oils. Because at boiling water, some of the essential oils dissolved in the water are available in the plant cells. This solution will gradually penetrate to the surface of the material and be attracted by the steam. And the water enters the material in the opposite direction and the essential oil continues to dissolve into this amount of water. But due to the size of the raw material, it will interfere with penetration and diffusion, resulting in very little amount of the oil obtained. And the amount of essential oil obtained is higher when the ingredients are chopped (fiber length $1 \div 4 \mathrm{~cm}$, width $0.1 \div 0.3 \mathrm{~cm}$, thickness $<0.1 \mathrm{~cm}$ ), the highest is in small grind size $(\varnothing=1 \div 3.5 \mathrm{~mm})$. The right size for the extraction process is to grind the iced skin for 1 minute to examine other factors. The selection of material size in this study was referenced to previous studies [19, 20]

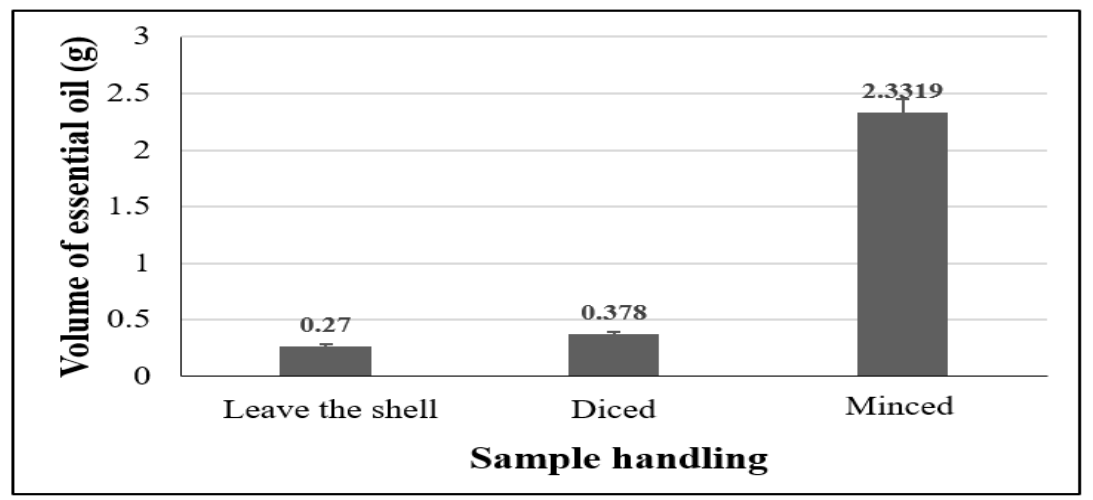

Fig. 3. The effect of the material size on the amount of essential oil obtained

\subsection{Investigation of raw material moisture}

The moisture content of the ingredients has an impact on the amount of essential oil obtained. In study Khorshidi Jalal, in order to investigate the influence of different methods of drying, extraction time the essential oil Rosemary (Rosmarinus officinalis L.). Three drying methods investigated were oven drying $\left(45^{\circ} \mathrm{C}\right)$, shade drying and sun drying. Four extraction times and three organ type were leaf, stem, mixed leaf and stem. Results showed that effect of drying methods on the essential oil percentage were significant [21]. In this study, fresh bark 
(77.37\% of moisture) obtained the highest amount of essential oil (Figure 4). For the shell which was dried for 1 hour (30.65\% of moisture), the amount of collected essential oil decreased clearly. And the amount of essential oil continued to decrease for the 2-hour drying shell $(2.62 \%$ of moisture). Because the material is thin, the heat easily affects the essential oil inside, so the longer the drying time, the easier it is to lose essential oil in the material. The suitable moisture for the extraction process is the fresh skin to examine the remaining factors.

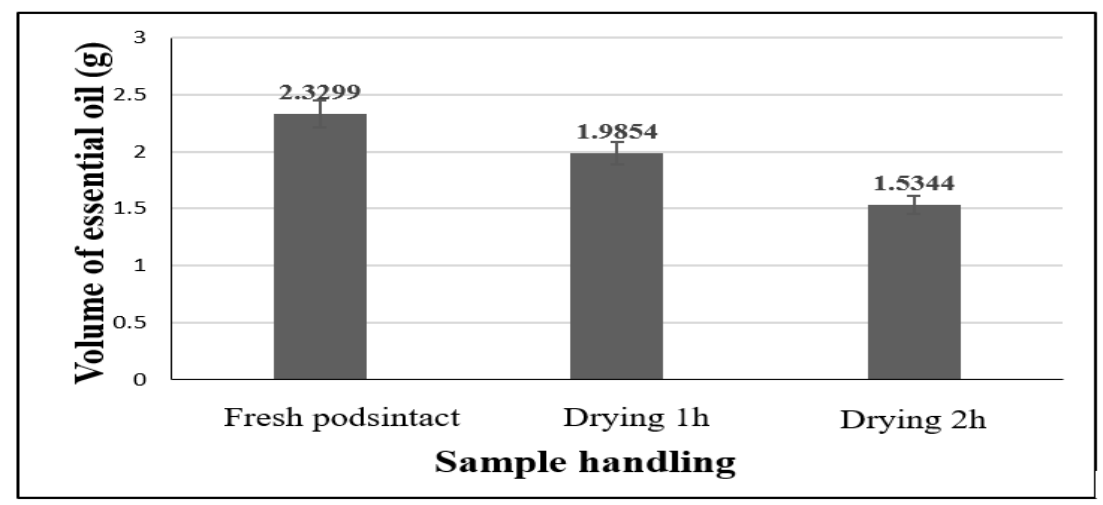

Fig. 4. Effect of raw material moisture on the amount of oil obtained

\subsection{Investigation of the ratio of raw materials / solvents}

The results from Figure 5 show that the ratio of ingredients / solvents affects the amount of essential oil obtained. Specifically, the amount of essential oil obtained is at least 1:4 ratio and highest at 1: 8 . In addition, we also see that the amount of oil obtained increases gradually as the ratio of raw materials / solvents increase from a ratio of $1: 4(2.1448 \mathrm{~g})$ to a ratio of 1 : $8(2.3913 \mathrm{~g})$, then slightly decreases as the ratio decline from $1: 8$ ratio $(2.3913 \mathrm{~g})$ to $1: 12$ ratio $(2.3539 \mathrm{~g})$. This can be explained that as the amount of solvent is small, it is not enough to diffuse into the material and boil in time to pull the essential oil out. Later, as the amount of solvent increases, causing the loss of a small amount of essential oil due to high temperature [22]. The suitable material / solvent ratio for extraction is 1: 8 was selected to examine the remaining factors.

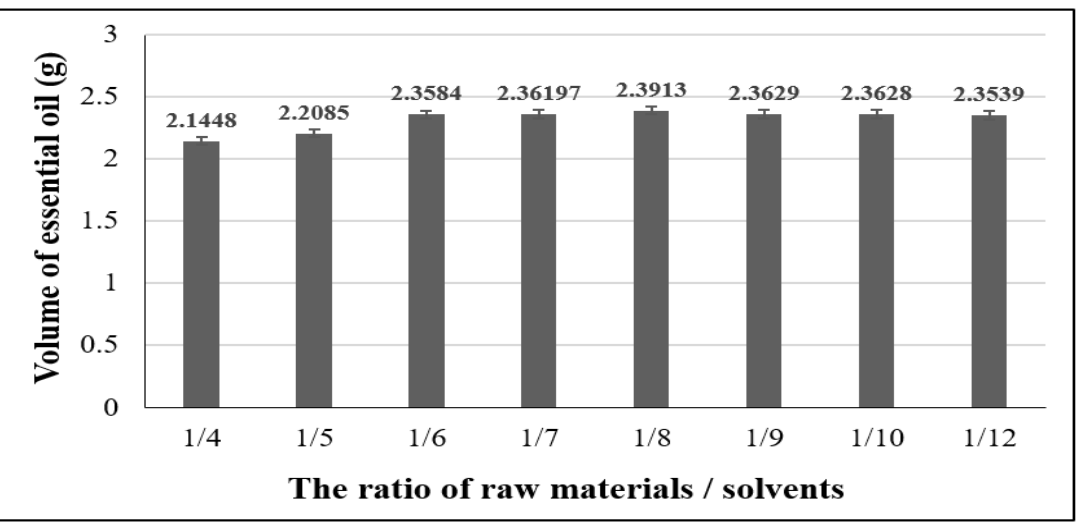

Fig. 5. Effect of material / solvent ratio on the amount of oil obtained 


\subsection{Investigation of extraction time}

Based on Figure 6, the volume of essential oil gradually increased from 1.17 at 20 minutes to 2.3903 at 60 minutes then decreased slightly and remained unchanged from 60 minutes $(2.3903 \mathrm{~g})$ to 120 minutes $(2.2043 \mathrm{~g})$. With the same volume of solvent, short initial time is not enough to absorb and diffuse essential oils out, leading to low volume of essential oils. Increasing extraction time to an appropriate period enable to draw all the essential oils in the material. However, if the distillation time continues to increase, the high temperature will cause the condenser system to work ineffectively, and promote essential oils votallity, leading to the loss of essential oil. The appropriate time for extraction is 60 minutes to perform extraction. This result is consistent with previous studies [23,24].

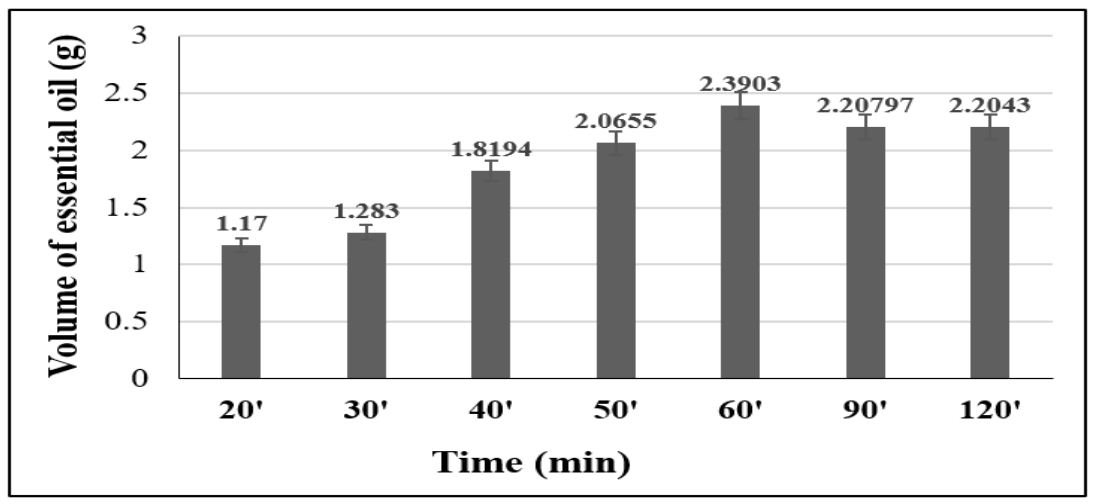

Fig. 6. The effect of extraction time on the amount of essential oil obtained

\subsection{Investigation of the purification of calamondin peel oil}

As shown in Figure 7 and Table 2, the highest essential oil recovery efficiency was achieved when purifying by the crystallization method, while the lowest efficiency was when purified by the 2 nd distillation method, crystallize - absorb and use $\mathrm{Na}_{2} \mathrm{SO}_{4}$ as anhydrous - filter. About sensory: Refining by the method of combining 2nd distillation, crystallization absorbing and using $\mathrm{Na}_{2} \mathrm{SO}_{4}$ as anhydrous - filter produced the best quality of essential oils (clear white, no water, characteristic aroma).

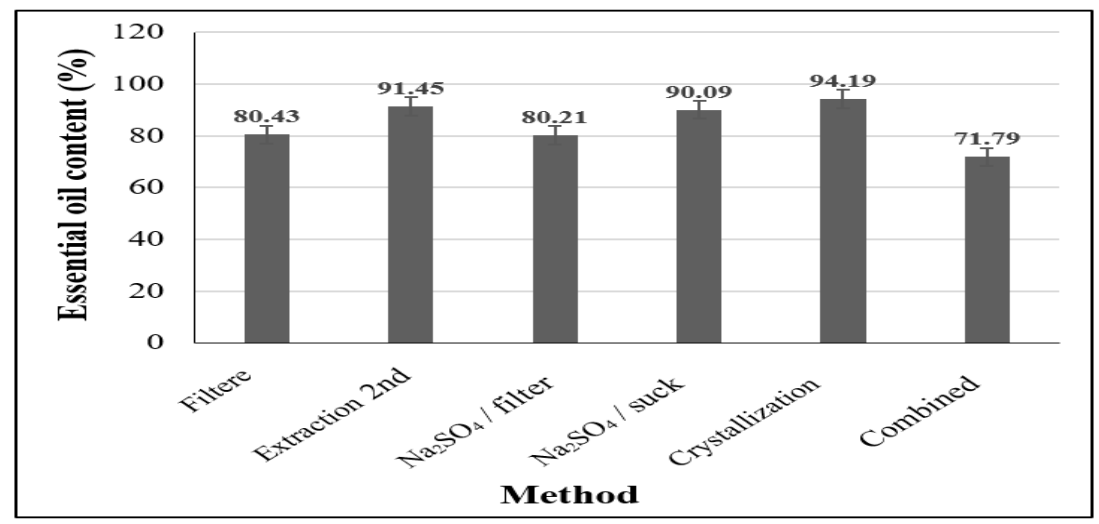

Fig. 7. The essential oil content is recovered through refining methods 
Table 2. Quality comparison of calamondin peel oil through purification methods

\begin{tabular}{|c|c|c|c|c|c|c|}
\hline Parameters & Filtered & $\begin{array}{c}\mathrm{Na}_{2} \mathrm{SO}_{4} \\
\text { anhydrous- } \\
\text { filter }\end{array}$ & $\begin{array}{c}\text { Use } \\
\mathrm{Na}_{2} \mathrm{SO}_{4} \\
\text { anhydrous- } \\
\text { suck }\end{array}$ & $\begin{array}{l}\text { Crystalli } \\
\text { zation - } \\
\text { suction }\end{array}$ & $\begin{array}{c}2^{\text {nd }} \\
\text { Extracti } \\
\quad \text { on }\end{array}$ & $\begin{array}{c}\text { Combined } \\
2^{\text {nd }} \\
\text { extraction, } \\
\text { crystallizati } \\
\text { on - } \\
\text { suction, } \\
\text { and } \\
\mathrm{Na}_{2} \mathrm{SO}_{4}, \\
\text { filter } \\
\end{array}$ \\
\hline $\begin{array}{l}\text { Sample volume } \\
(\mathrm{ml})\end{array}$ & \multicolumn{6}{|c|}{2} \\
\hline $\begin{array}{l}\text { Sample volume } \\
(\mathrm{g})\end{array}$ & \multicolumn{6}{|c|}{1.6767} \\
\hline $\begin{array}{l}\text { Volume of } \\
\text { recovered } \\
\text { sample } \\
(\mathrm{g})\end{array}$ & 1.3653 & 1.3449 & 1.5105 & 1.5793 & 1.5333 & 1.2037 \\
\hline $\begin{array}{c}\text { Recovery } \\
\text { performance } \\
(\%)\end{array}$ & 81.43 & 80.21 & 90.09 & 94.19 & 91.45 & 71.79 \\
\hline Color & $\begin{array}{l}\text { Light } \\
\text { white }\end{array}$ & Clear white & $\begin{array}{l}\text { Opaque } \\
\text { white }\end{array}$ & $\begin{array}{l}\text { Opaque } \\
\text { white }\end{array}$ & $\begin{array}{l}\text { Light } \\
\text { white }\end{array}$ & Clear white \\
\hline
\end{tabular}

\subsection{The results of GC - MS}

After purification, it was found that the content of the essential oils of the calamondin peel oil has changed: Limonene content increased from $90.4 \%$ to $92.87 \%$ the content of $\alpha$-Pinene increased from $1.01 \%$ to $1.03 \%$, content of Santolina on, $\alpha$-Terpineol no longer exists, the $\beta$ Pinene content did not change (3.36\%), and the remaining substances decreased (Table 3 and Table 4). In short, after being refined, the calamondin peel oil content is improved. Regarding the senses, the color is purer white, and has a characteristic aroma. Limonene content is enhanced whereas unnecessary ingredients was lost. The results of this study are consistent with the previous study by Chen et al. (2013) who had used the steam distillation. Results have shown that the obtained essential oil contained: Limonene $(91.15 \%), \alpha$-pine $(0.42 \%)$, $\alpha$-Terpineol (0.42\%), $\beta$-Pinene (0.55\%) and $\beta$-Myrcene (2.46\%) [25]. In addition, Limonene (77\%), $\alpha$-pine (1.1\%), and Myrcene (4.4\%) are the main ingredients in kumquat oil using the steam-enticing distillation method [26]. 
Table 3. Ingredients of crude calamondin shell oil were analyzed by GC/MS

\begin{tabular}{|c|c|c|}
\hline RT & Name & $\mathbf{\%}$ \\
\hline 5.514 & $\alpha$-Pinene & 1.01 \\
\hline 6.737 & Santolina triene & 0.54 \\
\hline 6.985 & $\beta$-Pinene & 3.36 \\
\hline 8.337 & Limonene & 90.40 \\
\hline 9.785 & $\begin{array}{c}\text { 1,6,10-Dodecatrien-3-ol, 3,7,11- } \\
\text { trimethyl-, [S-(Z)]- }\end{array}$ & 0.57 \\
\hline 11.741 & $\alpha$-Terpineol & 0.38 \\
\hline 11.816 & Octadecane, 6-methyl- & 0.41 \\
\hline 12.584 & Carvone & 0.53 \\
\hline 14.64 & $\begin{array}{c}\text { acetate } \\
\beta \text { 2,6-Octapaene }\end{array}$ & 0.49 \\
\hline 16.338 & & 0.91 \\
\hline
\end{tabular}

Table 4. Ingredients of refined calamondin shell oil were analyzed by GC / MS

\begin{tabular}{|c|c|c|}
\hline RT & Name & $\mathbf{\%}$ \\
\hline 5.514 & $\alpha-P i n e n e$ & 1.03 \\
\hline 6.737 & Santolina triene & - \\
\hline 6.985 & $\beta-P i n e n e$ & 3.36 \\
\hline 8.337 & Limonene & 92.87 \\
\hline 9.785 & $\begin{array}{c}1,6,10-\text { Dodecatrien-3-ol, 3,7,11- } \\
\text { trimethyl-, [S-(Z)]- }\end{array}$ & - \\
\hline 11.741 & $\alpha-T e r p i n e o l$ & - \\
\hline 11.816 & Octadecane, 6-methyl- & 0.27 \\
\hline 12.584 & $\begin{array}{c}\text { Carvone } \\
\text { acetate }\end{array}$ & 0.49 \\
\hline 14.64 & $\begin{array}{c}\beta-\text {-copaene } \\
\text { 2,6-Octadien-1-ol, 3,-dimethl-, }\end{array}$ \\
\hline 16.338 & & 0.16 \\
\hline
\end{tabular}

\section{Conclusions}

The present study has reported that the optimal conditions for extracting calamondin oil by using steam-enticing distillation included fresh unripe raw materials, raw material / solvent ratio $(\mathrm{w} / \mathrm{v}$ ) of 100/800, extraction time of 70 minutes and the sample size of $\varnothing 1 \div 3.5 \mathrm{~mm}$. Although the combined calamondin peel oil has better quality than crude oil with enhanced Limonene content, the combined refining process is expensive because it requires a lot of essential oils and also time-consuming.

\section{References}

1. T. H. Tran, T. D. Nguyen, Using soft computing approaches for orange (Citrus nobilis Lour . var . nobilis) oils extraction process Using soft computing approaches for orange (Citrus nobilis Lour . var . nobilis ) oils extraction process, in IOP Conference Series: Materials Science and Engineering, ICCEIB, 17-19 July 2019, Penang, Malaysia (2019).

2. X. T. Le, P.T.H. Ha, H.X. Phong, T.T. Hien and T.T.K. Ngan, Extraction of Essential oils and volatile compounds of Kaffir lime (Citrus hystrix D .C) by hydrodistillation method Extraction of Essential oils and volatile compounds of Kaffir lime (Citrus hystrix $D$. C) by hydrodistillation method, IOP Conference Series: Materials Science and Engineering, ICCEIB, 9-11 August 2020, Kuala Lumpur, Malaysia (2020)

3. T. Thi, K. Ngan, Q. M. Pham, C. H. Mai, Asian J. Chem, 32 (2020). 
4. T.C.Q. Ngo, H.D. Ngo, T.K.N. Tran, X.T. Le, C. M. Huynh, Microwave-assisted hydrodistillation and determines volatile components of essential oils from Calamondin (Citrus microcarpa) shells, in IOP Conference Series: Materials Science and Engineering, ICCEIB, 9-11 August 2020, Kuala Lumpur, Malaysia (2020).

5. T.C.Q. Ngo, Chemical Composition and Antibacterial Activity of Orange (Citrus sinensis) Essential Oils Obtained by Hydrodistillation and Solvent free Microwave Extraction Chemical Composition and Antibacterial Activity of Orange (Citrus sinensis) Essential Oils Obtained by Hydrodistillation and Solvent free Microwave Extraction, in IOP Conference Series: Materials Science and Engineering, ICCEIB, 9-11 August 2020, Kuala Lumpur, Malaysia (2020).

6. N.T.C. Quyen, N.T.N. Quyen, N. N. Quy, P. M. Quan, Evaluation of total polyphenol content, total flavonoid content, and antioxidant activity of Centella asiatica, in IOP Conference Series: Materials Science and Engineering, ICCEIB, 9-11 August 2020, Kuala Lumpur, Malaysia (2020).

7. N.T.C. Quyen, N.T.N. Quyen, L.T.H. Nhan, T.Q. Toan, Antioxidant activity, total phenolics and flavonoids contents of Pandanus amaryllifolius (Roxb.), in IOP Conference Series: Materials Science and Engineering, ICCEIB, 9-11 August 2020, Kuala Lumpur, Malaysia (2020).

8. N.T.C. Quyen, T.T.K. Ngan, H.X. Phong, T.T. Hien, L.T. Dung, Extraction of Kaffir Lime (Citrus hystrix DC.) essential oil by steam distillation and evaluation of chemical constituents, in IOP Conference Series: Materials Science and Engineering, ICCEIB, 911 August 2020, Kuala Lumpur, Malaysia (2020).

9. T.C.Q. Ngo, H.D. Ngo, T.K.N. Tran, X.T. Le, C.M. Huynh, Microwave-assisted hydrodistillation and determines volatile components of essential oils from Calamondin (Citrus microcarpa) shells, in IOP Conference Series: Materials Science and Engineering, ICCEIB, 9-11 August 2020, Kuala Lumpur, Malaysia (2020).

10. T.C.Q. Ngo et al., Yield and composition analysis of vietnamese lemon (citrus aurantifolia) essential oils obtained from hydrodistillation and microwave-assisted hydrodistillation, in IOP Conference Series: Materials Science and Engineering, ICCEIB, 9-11 August 2020, Kuala Lumpur, Malaysia (2020).

11. T.C.Q. Ngo, T.K.N. Tran, V.M. Nguyen, H.C. Mai, Optimization of green mandarin (Citrus reticulata) essential oil extraction using microwave-assisted hydrodistillation and chemical composition analysis, in IOP Conference Series: Materials Science and Engineering, ICCEIB, 9-11 August 2020, Kuala Lumpur, Malaysia (2020).

12. A. KOYASAKO and R. A. BERNHARD, J. Food Sci., 48, (2009).

13. H. H. Trinh, T. T. T. Nguyen, and T. N. Le, Sci. Technol. Dev. J., 12, 41-47(2009).

14. H. S. Choi and M. Sawamura, J. Agric. Food Chem., 48, (2000).

15. N.T. Lan Phi, Nishiyama, C. Choi, H. S. \& M. Sawamura, M. Biosci. Biotechnol. Biochem. 70, (2006).

16. H. Takeuchi, Y. Ubukata, M. Hanafusa, S. Hayashi, S. Hashimoto, J. Essent. Oil Res. 17, (2005).

17. S. Bourgou, F. Z. Rahali, I. Ourghemmi, M. S. Tounsi, Sci. World J., no. May (2012)

18. K. Keluarga et al., "Ournal of," 9, 4, (2020)

19. T. P. Dao et al., Optimization of essential oil yield from Vietnamese green pepper (Piper nigrum) using hydro-distillation method, IOP Conf. Ser. Mater. Sci. Eng., vol. 736, no. 2, 2020

20. K. Jalal, M. Rahmat, F. T. Mohammad, and N. Himan, Nat. Sci., vol. 7, no. 11, pp. 4244, (2009)

21. M. Öztürk, G. Tel, M. E. Duru, M. Harmandar, and G. Topçu, Nat. Prod. Commun., 4, 7, (2009)

22. T.H. Tran, T.N.Q. Nguyen, X.T. Le, H.X. Phong, \& T.B. Long, Optimization of 
operating conditions of Lemon (Citrus aurantifolia) essential oil extraction by Hydrodistillation Process using Response Surface Methodology. IOP Conf. Ser. Mater. Sci. Eng. 1092, 012094 (2021).

23. M. Golmohammadi, A. Borghei, A. Zenouzi, N. Ashrafi, \& M.J. Taherzadeh, Heliyon 4, (2018).

24. H.C. Chen, L.W. Peng, M.J. Sheu, Y.C. Chen, J. Food Drug Anal., 21, (2013).

25. P. Taylor, J.A. Pino, 37-41(2015). 